\title{
A formação de professores no âmbito da abordagem multirreferencial
}

\author{
João Batista Martins \\ Universidade Estadual de Londrina -PR
}

\section{Resumo}

Este trabalho é uma reflexão sobre educação, mais especificamente, sobre o processo de formação de professores. Para nos aproximar desta discussão partimos do pressuposto de que é necessário abordarmos tal problemática em sua complexidade. Para tanto, utilizamos a abordagem multirreferencial, que tem como perspectiva estudar os fenômenos educacionais considerando a heterogeneidade própria das relações educativas. Realizamos esta reflexão identificando vários aspectos do processo de formação de professores a partir dos campos da educação e da psicanálise. Tal percurso nos permitiu esclarecer e aprofundar algumas concepções, como as de educação, de relação pedagógica, da experiência e do vivido, sugerindo perspectivas para o processo de formação de professores.

Palavras-chave: Formação de professores; multirreferencialidade; psicanálise e educação.

\section{Teacher's education under the multi-referential approach}

\begin{abstract}
In this work we propose a reflection on education and, more specifically, on the process of teacher's education. To approach this discussion we assume the necessity of addressing this issue in its complexity. We used the multi-referential approach that has the perspective to study educational phenomena considering the heterogeneity typical of educational relationships. We are holding this discussion by identifying several aspects of the formation of teachers from the fields of education and psychoanalysis. This route allowed us to deepen and clarify some concepts: education, the teaching relationship, the experienced and lived, suggesting perspectives for the process of teacher's education.
\end{abstract}

Keywords: teacher formation; multi-referentiality; education and psychoanalysis.

\section{La formación de profesores en el ámbito del abordaje multirreferencial}

\section{Resumen}

Este estudio es una reflexión sobre educación, más específicamente, sobre el proceso de formación de profesores. Para acercarnos de esta discusión partimos del presupuesto de que es necesario abordar tal problemática en su complexidad. Para tanto, utilizamos el abordaje multirreferencial, que tiene como perspectiva estudiar los fenómenos educacionales considerando la heterogeneidad propia de las relaciones educativas. Realizamos esta reflexión identificando varios aspectos del proceso de formación de profesores a partir de los campos de la educación y del psicoanálisis. Tal recorrido nos permitió aclarar y profundizar algunas concepciones, como las de educación, de relación pedagógica, de la experiencia y del vivido, sugiriendo perspectivas para el proceso de formación de profesores.

Palabras-clave: formación de profesores; multirreferencialidad; educación y psicoanálisis. 


\section{Introdução}

Discutir a questão da formação de professores a partir da Psicologia, campo disciplinar no qual atuamos, coloca-nos, em princípio, diante de duas perspectivas. A primeira diz respeito à discussão sobre o papel da psicologia no contexto da educação e, mais especificamente no da formação dos professores: sua importância, suas correntes teóricas, sua articulação com outras disciplinas, etc. A segunda refere-se ao próprio processo de formação de professores. Diante destas duas possibilidades escolhemos a segunda perspectiva, uma vez que ela dá continuidade a uma discussão que já estamos realizando sobre os processos de formação, especialmente à formação de professores (Martins, 2000, 2004, 2009).

Tal opção se ancora em nossa prática profissional enquanto docente do curso de Psicologia e supervisor de estágio na área de Psicologia Escolar, no período de 1991 a 2001 - onde pudemos perceber que a aproximação do processo de formação de professores com o campo da psicologia se fazia numa perspectiva externa, ou seja, os docentes se apropriavam das teorias psicológicas e tentavam aplicá-las em seu cotidiano profissional.

Pretendemos, aqui, aproximar-nos da questão da formação de professores a partir de sua própria práxis, e neste contexto, dialogar com as teorias psicológicas de tal forma que elas nos possam ajudar a compreender esse processo enquanto vivência, enquanto experiência. Além disso, ao entendermos este processo em sua complexidade, vimos a necessidade de abordá-lo a partir de várias perspectivas disciplinares (multirreferencialmente), o que implica a realização de uma articulação entre várias disciplinas (Psicologia, Psicanálise, etc.). Nesse sentido, apresentaremos nossas ideias tendo como referência a abordagem multirreferencial desenvolvida por Jacque Ardoino (Ardoino, 1998; Martins, 2000, 2004).

Antes de prosseguir devemos esclarecer o que entendemos por formação. Marin (1995) publicou um trabalho onde esclarece alguns termos que estão vinculados à ideia de "formação continuada" no âmbito da educação. Essa autora, ao longo deste texto, aponta que o termo treinamento foi muitas vezes utilizado para se referir à formação continuada.

Em sua avaliação Marin afirma que este termo, quando inscrito no âmbito da Educação, remete-nos a algumas ideias inadequadas, como tornar destro, apto, capaz de realizar tarefas etc., em que o foco principal incide sobre a modelagem de comportamentos. Rejeitando esta postura, a autora afirma:

Penso que, em se tratando de profissionais de educação, há inadequação em tratarmos os processos de educação continuada como treinamento quando desencadearem apenas ações com finalidades meramente mecânicas. Tais inadequações são tanto maiores quanto mais as ações forem distantes das manifestações inteligentes, pois não estamos, de modo geral, meramente modelando comportamentos ou esperando reações padronizadas; estamos educando pessoas que exercem funções pautadas pelo uso da inteligência e nunca apenas pelo uso de seus olhos, seus passos ou gestos (Marin, 1995, p. $15-$ destaques nossos).

Nossa compreensão da noção de treinamento aproxima-se muito da leitura proposta por Marin, mas entendemos que o treinamento é uma modalidade de formação e que não se efetiva somente no âmbito da educação contínua, mas ocorre também no processo de formação inicial dos professores. Em ambas as esferas de formação - a inicial e a contínua - há certa ênfase no domínio das técnicas, das ferramentas, das estratégias de ensino, domínio que é cuidadosamente embasado em teorias científicas comprovadas. Em outras palavras, este tipo de formação - o treinamento - situa-se na ordem de um saber (conhecimento) e de um saber-fazer (prática) que em alguns momentos são concomitantes, em outros, dissociados.

Não obstante, a expectativa de Marin de que, a partir da formação continuada, os profissionais da educação exerçam funções pautadas pelo uso da inteligência, ainda não contempla a complexidade do fenômeno em pauta, pois ela se ancora num ideário que enfatiza o desenvolvimento dos aspectos cognitivos em detrimento de outros aspectos, como, por exemplo, a afetividade.

Em tal perspectiva - a da complexidade - vamos, ao longo deste trabalho, aproximar-nos de outras dimensões do processo de formação, especialmente daquelas que nos remetem para os aspectos subjetivos implicados nesse percurso. Assim, entendemos que os processos de formação - o inicial e o contínuo - devem ancorar suas preocupações em outra dimensão, que está além da do saber e da do saber-fazer, que é a do saber-ser, saber-devir, em que o vivido, o acompanhamento e a historicidade da experiência, a escuta dos sentidos (conscientes e inconscientes) que perpassam a relação ganham sua devida relevância.

Cabe ainda esclarecer que, do ponto de vista metodológico, este trabalho se revela uma pesquisa bibliográfica a partir da qual realizamos uma reflexão acerca da formação de professores tendo como marco teórico a abordagem de Jacques Ardoino. Para tanto, organizamos nossas reflexões a partir de textos relativos à teoria do autor, articulando-os com os referenciais da psicanálise (Freud) e da análise institucional. Nesse processo, ao conjugarmos as teorias em questão nós nos aproximamos da problemática da formação de professores a partir de várias perspectivas (multirreferencialmente).

\section{Da abordagem multirreferencial}

A perspectiva multirreferencial se propõe a abordar os fenômenos sociais, mais especificamente, os relativos à educação, de modo a estabelecer um novo "olhar", um olhar mais plural sobre o "humano", a partir da conjugação de várias correntes teóricas, o que se desdobra em uma nova 
perspectiva epistemológica na construção do conhecimento (cfe. Ardoino, 1998, 2000a).

Tal abordagem foi esboçada inicialmente por Jacques Ardoino, professor da Universidade de Vincennes (Paris VIII), e seu grupo de trabalho. O aparecimento da abordagem multirreferencial no âmbito das ciências humanas, especialmente no da educação, está diretamente relacionada com o reconhecimento da complexidade e da heterogeneidade que caracterizam as práticas sociais (Ardoino, 1998a).

Segundo Ardoino, análise multirreferencial é, inicialmente, uma resposta ao caráter extremamente complexo da prática social e, principalmente, das práticas educativas. Tal complexidade traz para aqueles que estão envolvidos com questões educacionais (professores, pedagogos, psicólogos e outros) uma série de dificuldades de leitura e de compreensão sobre suas próprias práticas, o que se desdobra em dificuldades de tomar decisões (Ardoino, 1998b). Se num primeiro momento a abordagem multirreferencial se caracteriza como uma questão metodológica, notamos, ao longo dos trabalhos de Ardoino, que suas preocupações se voltaram para as questões epistemológicas implícitas no procedimento proposto. Isso significa dizer que

[...]no lugar de buscar um sistema explicativo unitário [...] as ciências humanas necessitam de explicações, ou de olhares, ou de óticas, de perspectivas plurais para dar conta um pouco melhor, ou um pouco menos mal, da complexidade dos objetos (Ardoino, 1998c, p. 4).

Ou seja, a

[...] análise multirreferencial das situações das práticas dos fenômenos e dos fatos educativos se propõe explicitamente uma leitura plural de tais objetos, sob diferentes ângulos e em função de sistemas de referências distintos, os quais não podem reduzir-se uns aos outros. Muito mais que uma posição metodológica, trata-se de uma decisão epistemológica (Ardoino, 2000a, p. 254).

Assim, tal perspectiva de trabalho nos leva a abordar o problema da formação de professores a partir de várias questões, como, por exemplo, aquelas relacionadas com os objetivos e finalidades da Educação; aquelas vinculadas às relações pedagógicas e outras.

\section{Da Educação}

A Educação será entendida aqui como o conjunto das estratégias culturais que se estruturam nas sociedades tendo como objetivo assegurar sua continuidade material e sociocultural. Assim, para a consecução deste objetivo são criadas várias instituições, tais como a família, a escola, a Igreja e outras.

Nesse sentido, Ardoino (1995) nos esclarece que a

[...] educação aparenta, hoje, como uma função social global, intimamente associada à ideia de cultura, presa dentro de sua acepção antropológica mais ampla, visando desenvolver a transformação e o progresso social, (...), mais que a adaptação e a integração, (...) exercidas por numerosas e variadas instâncias. Porque ela é aculturação, através da tradição de conhecimentos e da aquisição de um saber-fazer e de um saber-ser; e ela expressa, o que é mais fundamental ainda, "visões de mundo", uma "cosmogonia" [...] (Ardoino, 1995, p. 6).

Assim, no plano macrossocial a Educação está vinculada ao suceder histórico das culturas, à sua continuidade; no entanto, pelo fato de ela situar-se no âmbito da transmissão e, por conseguinte, implicar pelo menos duas pessoas (um adulto e alguém mais jovem), ela também se inscreve no plano das microrrelações; e estas, por sua vez, colocam em jogo aspectos da convivência humana sobre os quais nós não temos controle: os elementos que dizem respeito às nossas vontades, aos nossos desejos, os quais se inscrevem na ordem do inconsciente.

A escola, enquanto uma instituição que se propõe transmitir um saber e um saber fazer, tem como modelo dominante a ideia de universalidade do conhecimento cientificamente estabelecido. Isto significa que as noções são as mesmas em todo tempo e em todo lugar. A vantagem dessa posição científica é que ela ao mesmo tempo é política - porque é uma garantia contra o arbitrário, pois a verdade, que preexiste, é única (a que se busca encontrar pelo trabalho científico) e é a mesma para todos.

Este modelo se vê confrontado quando no tocante à formação de adultos e à formação profissional contínua. Nestes domínios não nos localizamos mais sob o signo da universalidade, mas sob o signo da particularidade e da singularidade, uma vez que estes "alunos" trazem já uma experiência prévia, têm seus valores estabelecidos. Esta aproximação - do campo da formação com o campo da formação do adulto e da formação profissional - promove mudanças importantes no âmbito da educação escolar, principalmente em seus pressupostos epistemológicos, pois educadores, teóricos da educação e outros envolvidos com a área educacional se veem às voltas com questões relativas às dimensões temporal e histórica, as quais passam a ser consideradas como intrínsecas ao processo educacional.

Tais dimensões não se referem ao tempo quantitativo, aquele contado em número de horas de aula, em número de semanas de aulas ou em número de anos, aspectos que são externos ao processo de formação e dizem respeito à organização desse processo; elas se referem a uma "duração", a um tempo vivido, ao ritmo próprio de cada um. Esse tempo se estabelece a partir de nossos preconceitos, de nossos prismas, de nossos "filtros" e de nossa própria temporalidade

Além disso, o reconhecimento de tais dimensões leva-nos a pensar o processo educativo como algo que se situa na ordem do inacabamento - o que implica num saber-devir -, e a reafirmar seu aspecto relacional, pois tanto o educador como o educando se encontram vinculados à 
atividade educacional, embora, ocupando, obviamente, lugares diferentes, mas numa mesma situação de implicação ${ }^{1}$. Assim, os aprendizes não são mais percebidos a partir da perspectiva socioeconômica - aquela que os localiza exclusivamente por sua classe ou renda familiar - nem psicológica - aquela que os classifica através das medidas de idade mental ou quociente de inteligência, mas a partir das interações que entabulam no contexto escolar.

Isto pressupõe que o processo não será mais abordado a partir de atributos, ou estabelecido sobre o caráter das pessoas envolvidas, mas sim, enquanto relação - cujos efeitos elas mesmas alteram, promovendo mudanças pelo próprio jogo dessas interações. Pensar a educação sob essa ótica pressupõe um redirecionamento, principalmente no que tange às intencionalidades das práticas educativas.

De modo geral, as práticas educativas sempre localizaram a aprendizagem por parte dos estudantes na ordem de um saber e de um saber-fazer. O primeiro está relacionado com o conhecimento em si mesmo, já o segundo está relacionado com a capacidade de resolver problemas, de utilizar materiais, etc. Não existe, de imediato, uma preocupação com a formação do indivíduo - o que Ardoino denomina de saber-ser (Ardoino, 1971, 1973).

Não obstante, cabe salientar que as relações que se estabelecem no âmbito da educação na perspectiva exclusiva de um saber e/ou saber-fazer estão estruturadas a partir dos pressupostos do que se denominou na literatura de "educação tradicional" (Mizukami, 1986). Apesar das mudanças curriculares, das novas teorias sobre o ensino, dos novos esclarecimentos psicológicos sobre o processo de conhecimento, etc., ainda encontramos em nossas salas de aula uma relação que se estrutura verticalmente, na qual o professor detém o poder do conhecimento e o educando é aquele que recebe e incorpora tal conteúdo - correspondente à educação bancária descrita por Paulo Freire (1974, 1979).

Além disso, as relações que se estabelecem no âmbito da escola estão, geralmente, subsidiadas por uma inteligibilidade que privilegia as metodologias, os conteúdos, as grades curriculares, a organização burocrática etc., desconsiderando aspectos não lógicos, irracionais ${ }^{2}$, como os afetos, a emoção, as expressões do inconsciente, etc.

O fato de os educadores não reconhecerem estes elementos como inerentes à relação educativa nos remete à hipótese de que eles não estabelecem uma relação mais profunda com aqueles que estão trabalhando diretamente

1 A implicação é entendida aqui como: "[...] engajamento pessoal e coletivo do pesquisador em e por sua práxis científica, em função de sua história familiar e libidinal, de suas posições passadas e atual nas relações de produção e de classe, e de seu projeto sociopolítico em ato, de tal modo que o investimento que resulte inevitavelmente de tudo isso seja parte integrante e dinâmica de toda atividade de conhecimento. (Barbier, 1985, p. 120).

2 "[...] não lógico ou irracional não querem dizer aqui que escapam a toda lógica e que são irredutíveis a toda racionalidade, mas antes, que dependem de outras lógicas ou de outros tipos de racionalidade, uma vez que nossas óticas aristotélicas ou cartesianas familiares não permitem integrá-los realmente nem explicá-los eficazmente[...]" (Ardoino, 1971:. 66, n. 77).
- os estudantes. De certa forma os professores se "ausentam" dessas relações, principalmente quando os educandos apresentam dificuldades em sua vida acadêmica (geralmente acompanhadas por problemas comportamentais).

Como as relações que ocorrem no âmbito escolar são delimitadas por critérios que obedecem a determinadas lógicas (a da inclusão/exclusão, a da aprovação/reprovação e outras), o profissional que pode contemplar outras dimensões (geralmente definidas como "não lógicas"), que reconhece as vicissitudes da subjetividade, as expressões do inconsciente, etc. - necessárias para o processo de formação do indivíduo - fica desqualificado, abortado, pois estas dimensões dizem respeito a elementos que estão "localizados" na ordem do "não confiável", do "não mensurável".

O que queremos dizer com isso é que a educação deve se subsidiar não mais na "[...] tradição de um 'saber' ou de um 'saber-fazer', mas da comunicação de uma 'experiência', da aquisição de um 'saber viver' ou de um 'saber-ser'. A ação formativa [deve] produzir aqui um 'conhecimento experimental' dos problemas, que se pode opor ao conhecimento intelectual..." (Ardoino, 1971, p. 70).

Cabe registrar que "saber ser", "saber viver", como pressupõe Ardoino, implicam necessariamente a presença de um outro. É através do outro que o indivíduo chega a saber ser, a saber tornar-se. Assim, e na interação que o indivíduo "sabe-se sendo"; é na troca, no vivido, que ele aprende a "saber-ser": eis aqui o principal fundamento da educação.

\section{Da relação pedagógica}

Assinalamos anteriormente que os fenômenos educativos estão relacionados com os processos sociais próprios de cada sociedade e implicam questões relativas aos valores, aos devires, às finalidades das sociedades. Neste sentido, pensamos a educação como inscrita numa temporalidade, seja no plano da história de cada sociedade, seja no plano da vida de cada indivíduo.

Nossa sociedade, por sua vez, constitui-se a partir de um emaranhado de instituições (linguagem, normas, regras, etc.), e estas concorrem para assegurar sua manutenção (regulam a vida social) bem como o processo de socialização daqueles que vivem neste universo social. Para cumprir tal tarefa criaram-se algumas estruturas e mecanismos a partir dos quais se estabelece a transmissão de valores, de conhecimentos, de normas, de regras. Tais estruturas sociais caracterizam-se como organizações: as igrejas, as escolas, os clubes de serviços, etc.

Por outro lado, o exercício da transmissão traz em si mesmo um conjunto de ideias, de valores, etc., que muitas vezes não são expressos, que não são claros: é o que se conhece no âmbito da escola, por exemplo, por "currículo oculto" (Sacristán, 2000; Apple, 1994); é o que corresponde à ideia de Cifali (1998) sobre os rumores e os silêncios no âmbito dos estabelecimentos escolares; é o que expressam Ezpeleta e Rockwell através do conceito de "história não documentada" (Ezpeleta, \& Rockwell, 1986): são fenômenos que nem sempre são reconhecidos por aqueles que ocupam 
os lugares de poder (professores, diretores, orientadores, supervisores, psicólogos etc.) dentro da relação educativa. O não dito (assim identificamos essas situações) nos remete aos processos mais ou menos inconscientes que perpassam nossas relações, e diz respeito tanto aos aspectos relativos ao universo social como aos relativos às experiências e vivências das pessoas que estão envolvidas nas relações.

Dentro dessa dinâmica, o educador, ao assumir um lugar instituído/instituinte, põe em movimento um projeto que diz respeito tanto ao meio social em que está inserido como aos processos individuais relativos aos seus desejos - geralmente inconscientes e imprevisíveis.

Entender o ato de educar como projeto significa inserir a ação do educador num vir-a-ser histórico, numa relação entre um passado, um presente e um futuro - dimensões temporais que também são circunscritas tanto pelo universo social como pelos indivíduos (pelas suas experiências). Nesse sentido, Rios esclarece:

Ao organizarmos projetos, planejamos o trabalho que temos intenção de realizar, lançamo-nos para diante, olhamos para frente. Projetar é relacionar-se com o futuro, é começar a fazê-lo. E só há um momento de fazer o futuro - no presente. O futuro é o que viveremos como presente, quando ele chegar... trata-se de algo que se constata na nossa vivência do cotidiano. O presente ... traz no seu bojo o passado, enquanto vida incorporada e memória, e o futuro enquanto vida projetada... É isso que garante a significação do processo histórico (Rios, 1997, p. 73).

O projeto se estrutura através dos ideais que as pessoas constroem para si mesmas ao longo de suas vidas, o que está diretamente relacionado com os sentidos que elas atribuem a suas experiências; porém o projeto que se inscreve no âmbito da educação tem uma característica muito específica: implica necessariamente um outro.

Tal afirmação nos permite olhar o processo educacional de um outro ângulo, e nesse olhar o termo projetar assume um outro sentido: é a noção do projetar desenvolvido no contexto psicanalítico. Aqui, projetar indica a "operação pela qual o indivíduo expulsa de si e localiza no outro, pessoa ou coisa, qualidades, sentimentos, desejos, e mesmo 'objectos', que ele desdenha ou recusa em si." (Laplanche, \& Pontalis, 1967, p. 477). Esta noção vincula-se à ideia de que a relação entre educador e educando estrutura-se com base em um jogo de transferências ${ }^{3}$ (no sentido psicanalítico do termo) e reafirma essa ideia. Nesse jogo de transferên-

3 Freud assim define a transferência: "São novas edições, ou fac-símiles, dos impulsos e fantasias que são criados e se tornam conscientes durante o andamento da análise; possuem, entretanto, essa particularidade, que é característica de sua espécie: substituem uma figura anterior pela figura do médico. Em outras palavras: é renovada toda uma série de experiências psicológicas, não como pertencentes ao passado, mas aplicadas à pessoa do médico no momento presente." (Freud, 1901[1975], p. 113). No universo educacional, a transferência poderá ocorrer com o professor pois este poderá tornar-se a figura a quem serão dirigidos os interesses dos estudantes. cias ambos projetam para a relação, para o trabalho, para a aprendizagem, para os conteúdos programáticos, etc., ideais, qualidades e sentimentos que Ihes dizem respeito, porém são inconscientes.

Os estudantes nem sempre correspondem às expectativas dos educadores. Os primeiros, que também têm desejos, expectativas, vontades etc., confrontam os segundos, deixando-os a "ver navios", "sem tapete". O inverso também é possível: às vezes os educadores deixam os educandos perplexos, "sem rumos". Aqui cabe retomar uma consideração de Mauco:

O diálogo do educador e da criança é duplo. Ele se expressa sobre dois planos: inconsciente e consciente, que se ignoram mutuamente. É portanto de fato um diálogo a quatro vozes. A energia psíquica dos desejos que permanecem inconscientes entre os adultos e a criança determina a natureza de sua relação mais profundamente o que não pode tornar o diálogo verbalizado (Mauco, 1967, p. 249 destaques no original).

A indisponibilidade para a escuta das manifestações inconscientes - sejam as suas, sejam as do outro - deixa muitos professores e educadores em geral sem entender o que acontece em seu fazer pedagógico, principalmente quando se defrontam com situações em que se sentem confrontados, seja em sua autoridade, seja em seu poder (advindo do lugar institucional que Ihes é atribuído), seja em seus valores ou outros aspectos

Aquino, num estudo sobre a relação entre professor e estudantes, revela que esta relação se caracteriza como um "violento jogo de forças (ativas e reativas) com vistas à normatização da conduta alheia." (Aquino, 1996, p. 156). Isto significa que na relação pedagógica - e aqui, mais especificamente na relação entre professor e estudante não há, nas palavras de Aquino, "placidez ou completude", mas um constante redimensionamento dos "lugares" que os envolvidos na relação atribuem entre si, o que resulta num "ininterrupto campo de luta, sujeito a perdas e danos - o que significa um constante estado de tensão e embates imaginários, quer em relação ao lugar do outro, quer em relação ao próprio lugar." (Aquino, 1996, p. 156 - destaques no original).

Aquino chega a essa conclusão analisando os discursos construídos a partir dos "lugares" que, pela força da instituição, são ocupados pelos envolvidos na relação do processo de ensino/aprendizagem. Esses discursos são operacionalizados de tal forma que normatizam os comportamentos, as atitudes, etc.

Percebemos, por outro lado, que a perspectiva desenvolvida por Aquino nos leva a entender a relação entre professor e educando como um "círculo vicioso", que expressa uma redundância entre "ação e reação" em que, pela impossibilidade de superar os conflitos, não há espaço para uma atitude reflexiva acerca das relações que se estabelecem no cotidiano escolar. 
Nossa compreensão da relação, quanto ao aspecto assinalado, é bastante diferente. Entendemos que a relação educativa - uma vez compreendidos aspectos até então implícitos nas relações - permite aos educadores e educandos uma atitude mais reflexiva, atitude que pode revelar os mecanismos individuais, coletivos e institucionais que produzem e reproduzem o cotidiano escolar.

Esta última consideração nos leva a pensar que toda prática pedagógica se inscreve num campo social determinado por vários fatores - econômicos, sociais, políticos, antropológicos, etc. (Barbosa, 1998a), e também por fatores de ordem psicológica, que dizem respeito aos mecanismos inconscientes implícitos nas relações. Neste sentido, entendemos que o educador sempre se confrontará com a constituição pulsional de seus estudantes, ou seja, com manifestações inconscientes, e, sendo assim, ele deve ser capaz "[...] de inferir, a partir de pequenos indícios, o que está se passando na mente imatura desta [criança], de dar-lhe a quantidade exata de amor e, ao mesmo tempo, manter um grau eficaz de autoridade" (Freud, 1932[1975], p. 183).

Isso não significa que o professor deva assumir o papel de "analista" de seus educandos, aplicando-lhes o método psicanalítico para esclarecer o papel do inconsciente em suas vidas acadêmicas. $\mathrm{O}$ que podemos depreender da formulação de Freud é que este profissional deve ter uma postura de "escuta clínica" em relação às demandas que seus estudantes depositam na relação, uma postura que pressupõe uma implicação-distanciamento, o que lhe possibilitará estar efetivamente copresente na situação, sem perder sua especificidade e sua competência.

Tal perspectiva possibilitará ao professor reconhecer elementos até então desconsiderados em sua prática pedagógica, bem como reapropriar-se da experiência abrindo-se para o desconhecido e disponibilizando-se para a alteração ${ }^{4}$ (e por consequência para a heterogeneidade), para a escuta do inefável.

Esta posição remete o professor às questões que estão subjacentes aos comportamentos de seus educandos bem como ao jogo dos sentidos que sustentam as posições de cada um na situação pedagógica, um jogo permeado de conflitos, contradições, exasperações, agressões..., conflitos inevitáveis e necessários para que os estudantes possam exercer sua autonomia.

Em outro lugar (Martins, 1998), discutindo questões relativas à relação pedagógica, escolhemos uma metáfora para a ela nos referir. Nós a denominamos de "pescaria da traíra". A traíra é um peixe que, quando morde um anzol, nada rapidamente, puxando a linha com certa força, tentando se desvencilhar daquilo que a prendeu. Se o pescador não tiver paciência de trazer o peixe, soltar a linha, trazer o peixe, soltar a linha, trazer o peixe... quantas vezes forem neces-

4 Entendemos por alteração o processo a partir do qual o sujeito se transforma (se converte em outro) sem perder sua identidade, em função de influências (que podem ser positivas ou negativas) exercidas pelo outro (ou outros). De um modo geral, a alteração implica efeitos mais ou menos recíprocos entre pessoas, portanto, modificações. (cf. Ardoino, 2000b: 195-196). sárias, corre o risco de perdê-lo. Podemos pensar a relação entre professor e educando a partir dessa metáfora, visto que o professor, ao "fisgar", ou melhor, ao estabelecer um vínculo com o educando, estará sujeito a testes, contestações, agressões, projeções etc.; e se ele não tiver paciência, não assegurar o espaço de expressão para as demandas que ali são depositadas, corre o risco de "perdê-lo".

Cumpre lembrar que o exercício de tal posição traz em si mesmo uma série de dificuldades para o educador, e se ele não tiver clareza do que se passa, dificilmente estará disponível para as vicissitudes próprias à relação. A disponibilidade do professor poderá ser alcançada supondo-se várias situações: o reconhecimento de suas implicações em seu quefazer profissional, que lhe possibilitará reconhecer seus limites e possibilidades; o estabelecimento de uma relação que privilegie a heterogeneidade; o reconhecimento de que tal relação, por suas implicações e sua heterogeneidade, inscreve-se na ordem do imponderável, do imprevisto, daquilo que escapa.

No contexto escolar, assumir a heterogeneidade, a diferença, significa assumir que nem toda técnica, nem toda estratégia, é boa para todos; que nem todo o mundo aprende da mesma forma e no mesmo ritmo. A diferença e a alteração - ou seja, o jogo das influências mútuas - dispõem a relação numa temporalidade que lhe é própria e que muitas vezes contradiz a trajetória estipulada pela organização escolar para os estudantes. Ardoino, utilizando-se das metáforas de trajetória e do caminhante, assim explicita essa questão:

Pode-se dizer, de uma certa maneira, que os alunos, supostamente normais, que entram em tal idade... na mesma escola ou em escolas equivalentes, ao mesmo tempo, vão conhecer um trajeto análogo, um trajeto modelizado da mesma maneira. A trajetória é um trajeto, um itinerário organizado. Ao mesmo tempo, o ministro da educação, o reitor dessa universidade, o chefe do estabelecimento escolar, pensam absolutamente de forma natural a massa de alunos que eles devem administrar em termos de fluxo, de input, de output, de trajetória. Se essa trajetória modelizada é interrompida, temos o fracasso, não há outra saída. (...) Mas, ao mesmo tempo, cada um dos alunos, deve ainda ser considerado em termos de caminhante ${ }^{5}$. Enquanto a trajetória é uma imagem emprestada da astrofísica... a ideia de caminho está ordenada em função da intencionalidade, da afetividade, mas também das resistências, também do ritmo biológico próprio de cada um (Ardoino, 1998b).

Apesar de a Modernidade, em razão das exigências econômicas, indicar-nos uma abordagem do fenômeno educativo em termos de "trajetória", faz-se necessário que, ao mesmo tempo, "cada professor, cada formador... deve ser capaz de pensar a relação com o parceiro em termos de

\footnotetext{
5 Ardoino se inspira nos versos de A. Machado para desenvolver suas ideias. Os versos são os seguintes: "Caminante so tus huellas/ el camino y nada más./ Caminante no hay caminos/se hace camino al andar." (In BOHOSLAVSKY, 1991 : 27 - epígrafe).
} 
caminho, postura essa que traz em si mesma uma grande contradição" (Ardoino, 1998b).

Pensar o processo educativo sob o signo do "caminhante" significa inseri-lo na ordem do inacabamento, algo que não acaba ou que, na realidade, só termina com a morte. Tal ideia nos leva a entender a educação como uma noção complexa, na qual não se leva em consideração apenas a aquisição de conhecimentos - a transmissão dos saberes e do saber-fazer - mas, também, uma formação da afetividade, da responsabilidade: o que indicamos ao longo deste trabalho como saber-ser, saber tornar-se.

\section{Da formação de professores}

Tendo como ponto de partida as considerações anteriores, temos como pressuposto que um sistema educacional otimizado prima, principalmente, pela formação dos responsáveis por esse sistema. No contexto escolar, tal formação envolveria todos aqueles profissionais que estão presentes no processo de aprendizagem (aqui entendida em seu sentido mais amplo, não especificamente acadêmico) do estudante.

Como apontamos anteriormente, entendemos que o processo de formação se localiza na ordem do inacabamento, ou seja, situa-se num tempo histórico muitideterminado por fatores de várias ordens: política, econômica, social, psicológica, antropológica. etc. Este processo se inicia quando um indivíduo nasce e termina com sua morte. Tal perspectiva pressupõe que a formação inicial não é um fim em si mesma, que possibilite aos indivíduos inserir-se num determinado campo social: ela é apenas o início de um caminho que será percorrido ao longo da vida.

O processo de formação dos professores, por sua vez, não se dá num vácuo social. Ele se insere no âmbito do conjunto de demandas instituídas pela própria sociedade, já que são esses os profissionais que contribuirão para a formação acadêmica dos indivíduos, possibilitando-lhes o acesso ao universo dos conhecimentos sistematizados.

Quando se busca qualidade de ensino e uma escola comprometida com a formação para a cidadania, torna-se imprescindível repensar as bases epistemológicas e metodológicas que subsidiam o processo de formação de professores, no que se refere tanto à formação inicial como à contínua. Tal necessidade, por sua vez, torna-se mais presente à medida que reconhecemos e sentimos as constantes transformações decorrentes da sociedade - hoje multimidiática, globalizada, multicultural, etc.

Temos clareza dos limites implícitos ao processo de formação que se inscreve numa prática pedagógica tradicional. Aqui o professor é considerado como um mero "transmissor" de determinados conteúdos. Nessa perspectiva o processo de formação se limita a um saber - que diz respeito ao conteúdo da ou das disciplinas que ministrará quanto estiver trabalhando - e a um saber-fazer - relativo às metodologias que utilizará para transmitir os conteúdos referidos anteriormente. Como ele se posiciona como "transmissor", espera-se que o educando seja um "receptor" e que responda às demandas do processo de conhecimento com fidelidade - "repetindo o que aprendeu" quando solicitado.

Ora, quando introduzimos outras dimensões no processo, aquelas relativas às experiências, às subjetividades, ao vivido, às relações humanas, novas perspectivas se abrem para o processo de formação, especificamente em sua intencionalidade, pois as preocupações não recaem mais somente sobre um saber ou saber-fazer, mas sobre o saber-ser, saber-tornar-se.

\section{O "vivido", o "experienciado" e a formação de professores}

A ideia de "vivido" nos remete a uma discussão acerca das temporalidades que estão implicadas no processo educativo. Como assinalamos anteriormente, as pessoas inserem-se na relação educativa a partir de suas próprias experiências, de seus próprios prismas, de sua própria temporalidade. Isso significa dizer que nem todos aprendem da mesma forma, ao mesmo tempo e com uma mesma metodologia.

Trazer essa questão para o âmbito da formação significa reconhecer que os estudantes em formação também têm uma temporalidade, um "caminho" percorrido, trazem para o processo um conjunto de significados, etc.

No tocante àqueles em formação inicial, apesar de não terem experiência acumulada sobre "como dar aulas", eles trazem um conjunto de experiências com o processo educativo a partir de uma situação de estudantes, de aprendizes. Estas experiências deixam-Ihes "marcas" muito importantes. Quem, por exemplo, não teve uma admiração secreta por professores ou professoras? Uma paixãozinha por esse(a) ou aquele(a) professor(a)? Essa admiração e/ou essa "paixãozinha" têm um conjunto de significados - muitas vezes inconscientes - que interferem até mesmo na escolha da profissisão - no caso, a de professor.

Bohoslavsky (1991), trabalhando com os aspectos que circunscrevem a escolha vocacional, assinala que a opção profissional expressa uma relação direta ou indireta com o passado, o presente e o futuro, que, devido à situação de escolha dos indivíduos, são redimensionados. Nesse momento muitas experiências infantis são reeditadas e reelaboradas. O futuro, por sua vez, passa a representar um grande problema, pois é, ao mesmo tempo, desejado - à medida que inspira autonomia - e rejeitado - à medida que representa o desconhecido.

Além disso, para esse autor, a opção profissional também emerge de um contexto mais amplo, que diz respeito às ordens institucionais familiar, escolar e da produção, com as quais os indivíduos estabelecem relações. Tal posição possibilita a emergência de uma série de conteúdos desconhecidos que estão vinculados a processos psicológicos (fantasias, ansiedades, identificações) que muitas vezes são inconscientes.

Nesse sentido, no contexto da formação inicial, considerando que os estudantes nessa situação não têm ne- 
nhuma experiência prática, os professores poderiam proporcionar oportunidades de reflexão para que eles pudessem perceber os processos que influenciaram suas escolhas, pois isto Ihes possibilitaria ter clareza quanto aos motivos que os levaram a escolher a profissão de professor.

Ao se promoverem, durante o processo de formação inicial, situações que focalizem estes aspectos - como estágios, dinâmicas de grupo, estudo de casos, role playing, estudo sobre as histórias de professores, etc. - estar-se-á também promovendo o desenvolvimento social e pessoal do futuro profissional; ou seja, ao mesmo tempo em que os educandos em formação constroem ativamente um conhecimento acerca do mundo, eles também constroem um conhecimento acerca de si próprios. Estas experiências, por sua vez, possibilitarão aos futuros professores desenvolver uma postura de "escuta" com seus estudantes e consigo próprios.

Queremos dizer com isso que, se de um lado as escolhas (sejam elas profissionais, atitudinais, comportamentais, metodológicas, epistemológicas, etc.) trazem algo de opaco (sentidos que não são percebidos pelos indivíduos que estão na situação de escolha), por outro, o esclarecimento destes sentidos, principalmente quando as pessoas estão num encontro intersubjetivo - como é o caso da relação educativa - possibilitará uma ação mais refletida, mais madura.

Discutir o processo de formação na perspectiva multirreferencial implica considerar outras dimensões. Nessa direção, Candau (1992) assinala que tal processo deve ser considerado sob um enfoque multidimensional ${ }^{6}$.

Afirma a autora:

Nela o científico, o político e o afetivo devem estar intimamente articulados entre si e com o pedagógico. $\mathrm{O}$ domínio consistente de uma área específica supõe uma adequada compreensão da construção de seu objeto, dos diferentes enfoques metodológicos possíveis e suas respectivas bases epistemológicas, de sua lógica e de sua "linguagem". A dimensão política, em intima relação com a científica, supõe uma perspectiva clara do papel social do conhecimento em questão, do tipo de sociedade e de homem que se quer ajudar a construir, da realidade que se quer compreender, desvelar e transformar. Supõe também uma consciência crítica sobre o papel da ciência, da educação do professor na sociedade em que vivemos. Quanto à dimensão afetiva, afirma que ensinar supõe interação humana, envolvimento emocional, prazer, compromisso. Saber, prazer e compromisso transformador são dimensões que têm de ser trabalhadas em articulação contínua com a postura e o tratamento pedagógico indispensáveis a todo professor (Candau, 1992, p.47).

Podemos aproximar esta proposição de Candau à noção de implicação, já que a autora afirma a necessidade de reconhecer a dimensão afetiva durante o processo de

6 No contexto deste texto, chamaríamos de multirreferencial, conforme discutimos anteriormente. formação. Isto significa dizer que neste processo devem ser proporcionadas situações em que os indivíduos possam vivenciar, seus engajamentos pessoal e coletivo e refletir sobre eles, entendendo que tal engajamento é circunscrito pela sua história familiar e libidinal, por suas posições passadas e atuais nas relações de produção e de classe, e por seu projeto pessoal.

Tal aproximação nos permite afirmar a importância de reconhecer as manifestações inconscientes. Entendemos que esta dimensão, apesar de ser desconsiderada completamente nos processos de formação, remete-nos para o conjunto de significados, de sentidos, que influenciam as escolhas, as atitudes, as decisões, etc., ou seja, remete-nos para o vivido, para as experiências.

Afirmar a necessidade de resgatar a experiência, a temporalidade de cada um fica-nos mais evidente quando pensamos na educação contínua. Segundo Candau (1992), existem três afirmações que subsidiam os processos de formação contínua e que buscam novas perspectivas de atuação e intervenção, que passamos a expor.

A primeira afirmação ressalta a necessidade de reconhecermos que o locus da formação a ser privilegiado é a própria escola. Trata-se de trabalhar com o corpo docente de uma instituição favorecendo processos coletivos de reflexão e intervenção na prática pedagógica concreta. O processo de formação terá como ponto de partida as necessidades reais dos professores, os problemas de seu dia a dia.

A segunda afirmação assinalada por Candau diz respeito a reconhecer o saber docente como referência fundamental para o processo de formação contínua. Queremos dizer com saberes docentes aqueles conhecimentos relativos aos conteúdos, a metodologias de ensino e, de modo especial, aos saberes da experiência. Para Candau, devemos valorizar esses saberes, pois eles são

[...] o núcleo vital do saber docente, e a partir do qual o professor dialoga com as disciplinas e os saberes curriculares. Os saberes da experiência se juntam no trabalho cotidiano e no conhecimento do meio. São saberes que brotam da experiência e são por ela validados. Incorporam-se à vivência individual e coletiva sob forma de habitus e de habilidades de saber fazer e de saber ser (Candau, 1992, p. 59).

Tal noção (saberes da experiência) está muito próxima do que temos chamado aqui de "vivido", de "experienciado".

Aúltima afirmação sobre formação contínua apontada por Candau indica que os processos de formação contínua devem-se caracterizar pela heterogeneidade, de tal forma que contemple as diferenças do conjunto dos professores; ou seja, devemos tomar consciência de que as necessidades, os problemas, as buscas dos professores não são as mesmas nos diferentes momentos do seu exercício profissional. Tal perspectiva rompe com modelos padronizados de formação contínua e com a criação de sistemas diferenciados que permitam aos professores explorar e trabalhar 
diferentes momentos de seu desenvolvimento profissional, conforme suas necessidades específicas.

Cabe ainda registrar que nem a formação inicial nem a formação contínua devem ser concebidas como um meio de acumulação de conhecimentos, mas sim, como uma perspectiva de trabalho que implique reflexibilidade crítica sobre as práticas e possibilite a construção e a reconstrução permanente de uma identidade pessoal e profissional.

\section{Conclusões}

Tomamos a formação de professores entendendo-a como uma política de valorização do desenvolvimento pessoal/profissional dos professores e das instituições escolares, uma vez que supõe condições de trabalho propiciadoras da formação contínua dos professores no local de trabalho ou em redes de autoformação em parceria com outras instituições de formação. É preciso

... pensar um educador voltado para a compreensão de um modo de ser voltado para a compreensão de seus educandos, de como eles se apresentam na profundeza de seus valores; na complexidade de seus perfis e na leveza de sua criação enquanto sujeitos que se encontram no mundo cotidiano, contínua e bravamente se criando e se remodelando. É escutar e apreender o caráter original da ação do sujeito onde se encontra a criação e não a reprodução (Barbosa, 1998b, p. 83-84- destaques nossos).

Estar disponível para o outro significa, por outro lado, estar disponível para si mesmo. Tal perspectiva nos leva a pensar um processo de formação em que o mais importante não sejam os resultados, as notas, as presenças, as faltas e a avaliação, mas sim, as relações intersubjetivas, pois com estas, a partir de uma prática reflexiva, o professor poderá elaborar uma crítica às condições de trabalho nas quais está inserido e estabelecer uma relação de escuta tanto de seus estudantes como de si mesmo, situação que lhe permitira entrar em contato com os medos e angústias que, de certa forma, rodeiam o processo educacional (Barbosa, 1998b).

Entendemos que tal proposição nos direciona para uma nova concepção do quefazer pedagógico, que permita compreender a atividade educacional como processo em sua historicidade; um quefazer pedagógico que contemple e reconheça as implicações, as alterações, as subjetividades, de modo que o conhecimento seja construído a partir da realidade escolar, das vivências e suas vicissitudes; enfim, um quefazer que possa ser compreendido em sua complexidade.

A abordagem multirreferencial, à medida que considera a complexidade dos fenômenos educativos, apresenta-se para nós como uma ruptura, pois traz em si mesma o exercício da heterogeneidade, o que possibilitará àqueles que estão em formação pautar suas práticas por uma ética que tenha como princípio básico o respeito e a convivência, o múltiplo e o pluri, seja em termos individuais seja em ter- mos culturais, de forma a assegurar uma com-vivência no espírito da democracia.

\section{Referências}

Apple, M. (1994). Repensando ideologia e currículo. Em Moreira, A. F. Moreira, \& T. T. Silva (Orgs.). Currículo, cultura e sociedade (pp. 39-57). São Paulo: Cortez.

Aquino, J. G. (1996). Confrontos na sala de aula: uma leitura institucional da relação professor-aluno. São Paulo: Summus.

Ardoino, J. (1971). Psicologia da educação: na universidade e na empresa. São Paulo: Herder/Edusp.

Ardoino, J. (1973). Apprendre a être. Cahiers Pedagogiques, p. 18-31.

Ardoino, J. (1995). Education. Em Le directeur et l'intelligence de l'organization: Repéres et notes de lectura (pp. 5-6). Ivry: ANDESI.

Ardoino, J. (1998). Abordagem multirreferencial (plural) das situações educativas e formativas. Em J. G. Barbosa (Coord.). Multirreferencialidade nas ciências e na educação (pp. 24-41). São Carlos: Editora da UFSCar, 1998.

Ardoino, J. (1998a). Análise institucional: gênese, atualidade e perspectivas. Palestra proferida na Universidade Federal do Rio Grande do Sul - Faculdade de Psicologia, no dia 13.10.

Ardoino, J. (1998b). Abordagem multirreferencial: a epistemologia das ciências antropo-sociais. Palestra proferida na Pontifícia Universidade Católica do Rio Grande do Sul - Faculdade de Psicologia, no dia 14.10 .

Ardoino, J. (1998c). A formação do educador e a perspectiva multirreferencial. Mini-Curso ministrado na Universidade Federal de São Carlos - Departamento de Educação - Programa de PósGraduação em Educação, no período de 15 a 16.10.

Ardoino, J. (2000a). Approche multiréferentielle. Em Les avatars de l'éducation: problématiques et notions em devenir (pp. 254-260). Paris: PUF.

Ardoino, J. (2000b). Altération. Em Les avatars de l'éducation: problématiques et notions em devenir (pp. 195-196). Paris: PUF.

Barbosa, J. G. (1998a). Apresentação. Em J. G. Barbosa (Org.). Reflexões em torno da abordagem multirreferencial (pp 7-10). São Carlos: Editora da UFSCar.

Barbosa, J. G. (1998b). A formação em profundidade do educador pesquisador. In: J. G. Barbosa (Org.). Reflexões em torno da abordagem multirreferencial (pp. 73-87). São Carlos: Editora da UFSCar. 
Bohoslavsky, R. (1991). Orientação vocacional: a estratégia clínica (8 ed.). São Paulo: Martins Fontes.

Candau, V. M. (1992). Universidade e formação de professores: que rumos tomar. Em V. M. Candau (Org.). Magistério: construção cotidiana (pp. 31-68). Petrópolis: Vozes.

Cifali, M. (1993). Silences et rumeurs dans les stablissements scolaires: problemes de communication? Apports psychanalytiques. Recuperado: 25 out. 1998. Disponível: http://agora.unige.ch/sedcifali/Silence.html.

Ezpeleta, J., \& Rockwell, E. (1986). Pesquisa participante. São Paulo: Cortez/Autores Associados.

Freire, P. (1974). Uma educação para liberdade (4ed.). Porto: Dinalivros.

Freire, P. (1979). Pedagogia do oprimido (7ed.). Rio de Janeiro: Paz e Terra.

Freud, S. (1932[1975]). Novas conferências em psicanálise. Em Edição Standard Brasileira das obras completas de Sigmund Freud (vol. XXII). Rio de Janeiro: Imago.

Laplanche, J., \& Pontalis, J-B. (1967). Vocabulário de psicanálise. São Paulo: Martins Fontes.

Marin, A. J. (1995). Educação continuada: introdução a uma análise de termos e concepções. Cadernos Cedes, 36, 13-20.
Martins, J. B. (1998). Multirreferencialidade e educação. Em J. G. Barbosa (Org.). Reflexões em torno da abordagem multirreferencial (pp 21-34). São Carlos: Editora da UFSCar.

Martins, J. B. (2000). Abordagem Multirreferencial: Contribuições epistemológicas e metodológicas para o estudo dos fenômenos educativos. Tese de doutorado. Universidade Federal de São Carlos, São Carlos, SP, Brasil

Martins, J. B. (2004). Contribuições epistemológicas da abordagem multirreferencial para a compreensão dos fenômenos educacionais. Revista Brasileira de Educação, 26, 85-94.

Martins, J. B. (2009). Contribuições da psicanálise para a formação de professores. Revista Iberoamericana de Educación (Online), $48,5,1-14,2009$

Mauco, G. (1967). Psychanalyse et éducation. Paris: Aubier Montaigne.

Mizukami, M. G. (1986). Ensino: as abordagens do processo. São Paulo: EPU.

Rios, T. A. (1997). Ética e competência. (5 ed.). São Paulo: Cortez.

Sacristán, J. G. (2000) O currículo: uma reflexão sobre a prática. Porto Alegre: ArtMed.

\section{Sobre o autor}

João Batista Martins (jbmartin@sercomtel.com.br)

Depto de Psicologia Social e Institucional - Universidade Estadual de Londrina

Pós-Doutor em Educação - UnB

Texto elaborado a partir de Tese de Doutorado intitulada "Abordagem Multirreferencial: Contribuições epistemológicas e metodológicas para o estudo dos fenômenos educativos" (2000) e do artigo "Contribuições da psicanálise para a formação de professores", publicado na Revista Iberoamericana de Educación (Online), v. 48/5, p. 1-14, 2009.

Este trabalho foi elaborado a partir de ideias já esboçadas em Autor, 2000 e 2009. 